\title{
Chronic pain: the burden of disease and treatment innovations
}

\author{
S. Monti, R. Caporali \\ Unità Operativa Complessa di Reumatologia, IRCCS Fondazione S. Matteo, Pavia. Università di Pavia
}

\begin{abstract}
SUMMARY
Musculoskeletal conditions are the most frequent cause of chronic pain and affect around 1 in 5 adults in Europe. When chronic pain occurs, it becomes disease itself, with substantial clinical, social and economic impact. Efficacy and tolerability problems are encountered with all therapeutic strategies available to treat musculoskeletal pain. This often limits effective analgesia and patients' long term compliance, with the result that chronic pain is persistently underestimated and undertreated. Tapentadol is a novel, centrally acting analgesic that has been recently commercialized for the treatment of chronic pain. This new molecule, by combining two distinct mechanisms of action, $\mu$-opioid receptor agonism (MOR) and noradrenaline reuptake inhibition (NRI), introduces a new pharmacological class called MOR-NRI. Several studies demonstrated promising results in the management of both nociceptive and neuropathic pain and good tolerability profile, particularly concerning side effects, compared to traditional opioids. This novel analgesic represents a possible therapeutic option also in the rheumatologic field, particularly in the treatment of osteoarthritis and low back pain.
\end{abstract}

Key words: musculoskeletal diseases, chronic pain, opioids, tapentadol.

Reumatismo, 2015; 67 (2): 35-44

M usculoskeletal diseases represent a clinically and socio-economically relevant issue involving hundreds of million of people around the world (1). The burden of these conditions can be further increased when severe long-term pain occurs. Prolonged triggers result in activation of the pain matrix in the brain and neuronal plasticity with the result that pain perception can be elicitated even without a peripheral stimulus (2). Pain is defined as chronic when it lasts beyond the expected healing time or over a 3-month-period (3). At this stage, chronic pain becomes disease itself, with substantial clinical, psychological, social and economic impact.

\section{RELEVANCE OF MUSCULOSKELETAL CONDITIONS}

Rheumatic diseases are a prominent cause of chronic pain (4). Musculoskeletal conditions affect one in four adults across Europe (5). The MAPPING study, a cross-sectional epidemiological study analyzing the prevalence of musculoskeletal conditions in an Italian population sample, revealed that these conditions are common in the general adult population, particularly in women and with increasing age. The overall prevalence of musculoskeletal conditions was $26.7 \%$. The most frequent diagnosis was symptomatic peripheral osteoarthritis (OA) (8.95\%), followed by soft tissue disorders $(8.81 \%)$, low back pain $(5.91 \%)$, and inflammatory rheumatic diseases (3.06\%) (6). Recent estimates on the prevalence of rheumatic diseases indicate that in the United States nearly 27 million people are affected by clinical OA, 5 million have fibromyalgia, up to 3 million have self-reported gout, rheumatoid arthritis affects 1.3 million adults, spondylarthritides from 0.6 to 2.4 million adults (4).

\section{EPIDEMIOLOGY AND BURDEN OF MUSCULOSKELETAL CHRONIC PAIN}

Pain is almost constantly associated with musculoskeletal diseases. A review of prevalence studies indicates that almost one-fifth of adult populations report widespread pain (fibromyalgia), one-third shoulder pain and
Indirizzo per la corrispondenza: Sara Monti

Policlinico S. Matteo

Pz.le Golgi, 3 - 27100 Pavia, Italy E-mail: sara.saramonti@gmail.com 
up to one-half low back pain in a 1-month period (7). A survey on different health aspects in the European Union, the "Eurobarometer Report on Health" $(1,8)$, included a question on musculoskeletal pain. As many as $32 \%$ of all respondents and $44 \%$ of those 55 years and over reported to have experienced muscle, joint, neck or back pain affecting their daily activities in the previous week. Up to $25 \%$ of all respondents reported chronic restrictive musculoskeletal pain lasting more than 3 months at some point in their life. A lower educational profile and female sex were risk factors for developing musculoskeletal pain $(1,8)$. In 2008 a questionnaire conducted by the National Health and Wellness Survey on 53,525 adults in five European countries (United Kingdom, France, Spain, Germany and Italy) revealed that $22 \%$ of the subjects had suffered from pain within the last month, of whom $44 \%$ experienced pain daily (9). Back pain was the commonest condition causing chronic pain $(71 \%)$, followed by joint pain, while oncologic pain accounted for only $1 \%$ of the patients. Pain severity correlated with the general health and mental status, with high incidence of depression (35\%), anxiety $(42 \%)$ and sleep difficulties $(58 \%)$ compared to the general population $(2,9)$.

The burden of chronic musculoskeletal pain is relevant, often leading to functional disability and potentially to severe impairment of normal daily living activities. About one third of the Italian population is reported to have sought medical advice for musculoskeletal complaints in the previous year (10). OA is the most common joint disorder and accounts for more disability among the elderly than any other disease (1). Health related quality of life (HRQOL) of older patients with OA has been reported to be lower than that of the community-matched cohort and similar to scores from patients with depression or advanced cancer (1). $\mathrm{OA}$ is listed among the leading causes of burden of disease expressed in DALYs in Europe. One DALY can be defined as the loss of 1-year of healthy life. DALYs are calculated as the sum of the years of healthy life lost owing to premature mortality (YLL) and the years lived with disabil- ity (YLD) (1). The MAPPING study evaluating the quality of life in patients with musculoskeletal diseases demonstrated that severe chronic pain (grade III and IV), associated with high disability, was reported more commonly in the inflammatory rheumatologic diseases $(22.7 \%)$, followed by the low back pain (12.6\%) group, and was significantly lower in patients with osteoarthritis and soft tissue disorders (11). This study also demonstrated a significant correlation between pain intensity and health status evaluated with the short form (SF36) questionnaire (11).

\section{TREATMENT OVERVIEW: THE NEED FOR NEW THERAPEUTICAL OPTIONS}

From the previously mentioned evidence, it is clear that chronic pain has a substantial medical and social impact. Optimal management of OA requires a combination of non-pharmacological and pharmacological modalities. Initial treatment should focus on non-pharmacological approaches (eg, lifestyle, physical therapy). For patients whose symptoms are not controlled by these approaches, pharmacological treatments should then be considered (12). Nevertheless, data focusing on the pharmacologic prescription modalities of general practitioners and specialists do not reflect the importance of an effective treatment of chronic pain.

An insight of the epidemiology of musculoskeletal disorders in Italy revealed that at least $25 \%$ of the $48,136,832$ Italians aged over 18 years (2006 census) report musculoskeletal disorders, but nearly $40 \%$ don't seek any medical attention and only $4 \%$ of them are followed by rheumatologists (13). The American Academy of Pain Medicine estimates that more than 4 every 10 patients with moderate-to severe pain don't get adequate relief from analgesics; a quarter of patients change health care professionals more than once because of perceptions of suboptimal pain care (14). Data from the AMICA study analysing pharmacologic and non-pharmacologic prescription patterns of general practitioners and specialists 
to treat symptomatic OA suggest that a consistent number of patient don't receive any treatment at all, while the majority of them are treated with mild analgesics, NSAIDs or coxibs (10). In the latest years, we are assisting to a decline in the use of NSAIDs to treat OA pain. This particularly affects elderly patients, in spite of the higher prevalence of musculoskeletal chronic pain in this population. The descending trend is probably due to the increasing awareness of potential side effects of NSAIDs, particularly affecting the gastrointestinal system, in the setting of often multipathological, complex patients (15). A striking decrease in the use of coxibs was also registered after rofecoxib withdrawal from the market due to the evidence of an increased risk of myocardial infarction (16). An Italian study analysing the effect on drugs prescription after rofecoxib withdrawal showed a reduction in coxib use from $4.4 \%$ to $1.6 \%$. A very low prevalence of weak opioids prescription $(0.4 \%)$ was also reported (16). The American Geriatrics Society recommendations suggest that acetaminophen should be the first choice pharmacotherapy in the elderly; NSAIDs and COX-2 selective inhibitors may be considered rarely, and with extreme caution, in highly selected individuals. These patients should routinely be assessed for GI and renal toxicity, hypertension, heart failure. Patients with moderate to severe pain, pain-related functional impairment, or diminished quality of life because of pain should be considered for opioid therapy (17). Surprisingly, despite guidelines recommendations, the reduced prescription rate of anti-inflammatory drugs was not followed by an increase in the use of different medications with proved efficacy, such as acetaminophen or weak opioids $(15,16)$.

The tendency to avoid opioid use in the treatment of musculoskeletal pain is not justified by published evidence. The expert consensus recommendations for the management of hip and knee OA (OARSI group) deriving from a systematic review of existing guidelines underlines, with high levels of evidence and consensus, that weak opioids can be considered for the treat- ment of refractory pain, when other pharmacological agents have been ineffective or are contraindicated. In exceptional circumstances stronger opioids could also be prescribed (12). A recent Cochrane review also reported some evidence of efficacy and function improvement in patients treated with opioids for chronic back pain (18). As previously mentioned, weak opioids can be a valid option also in the elderly patients at higher risk for anti-inflammatory-related adverse effects (17).

The American Heart Association lists opioids among medications with a more favourable safety profile, together with acetaminophen, that should be preferred to NSAIDs and particularly coxibs, in patients with coronary artery disease (19). Opioids including tramadol represent a valid option after maximizing non-opioid pain relief strategies also in patients with back pain according to the American Pain Society guidelines (14). Opioids may also be appropriate for patients with neuropathic pain who have not achieved adequate analgesia despite treatment with antineuropathic agents (eg anticonvulsants and tricyclic antidepressants/dual reuptake inhibitors) (14). Two systematic reviews of placebocontrolled trials of opioids for non-cancer pain conditions (mainly OA and neuropathic pain) found opioids to be moderately effective, with a mean decrease in pain intensity with opioids of at least $30 \%$ in most trials (20). A meta-analysis of 18 clinical trials in OA patients including a total of 3244 participants treated with opioids demonstrated good efficacy in decreasing pain intensity and conferring modest functional benefits (21).

Great differences exist in analgesic prescription among different European countries. Opioids are prescribed much more readily in Northern Europe compared to the South (including Italy) or the East, leading to the impression that pain treatment seems to be driven mainly by tradition and personal experience rather than by international guidelines (22).

This "opiophobia" can partly be explained by the fear of adverse events induced by opioids. A systematic review and meta- 
analysis of 34 trials including 4212 patients provided information on adverse events related to opioid use in treating musculoskeletal pain. About one patient every two experienced at least one adverse event, and one in five discontinued treatment because of adverse events. Nausea (21\%), constipation $(15 \%)$, dizziness $(14 \%)$, and drowsiness or somnolence $(14 \%)$ were the most common (23). A recent review on potential adverse effects of long-term opioid therapy (24) confirmed that gastrointestinal (GI) side effects are the most common ones. Up to $40 \%-45 \%$ of patients on opiate therapy experience constipation, while $25 \%$ experience nausea.

Opioid neurotoxicity, dizziness and sedation are a significant issue, especially among the elderly. Other possible adverse reactions are: association between sleepdisordered breathing and chronic opiate use in a dose-dependent fashion, opiateinduced hypogonadism, and possible negative cardiovascular effects such as increased risk of myocardial infarction or heart failure, as well as increased pneumonia risk among the elderly, possibly associated with immunosuppression (24). Tolerance and addiction are also relevant issues when prescribing opioids. Risk factors for opioid abuse are history of previous drug conviction, mental health disorders, past alcohol or illicit drug abuse (25). Moreover, opioid treatment may not be effective because of individual variations to pure $\mu$-opioid agonist therapies and different degrees of central sensitization. In chronic musculoskeletal pain conditions descending inhibitory pain pathways may be disrupted and drugs with different mechanisms of action (eg, serotonin or noradrenalin reuptake inhibition) may be more effective, compared to pure $\mu$-opioid receptor agonists (26-27).

The previous results suggest that efficacy and tolerability problems are encountered with all therapeutic strategies available to treat musculoskeletal pain. This often limits effective analgesia and patients' long term compliance, with the result that chronic pain is persistently undertreated. The need for new therapeutic options is therefore stringent.

\section{TAPENTADOL}

Tapentadol is a novel, centrally acting analgesic that has been recently commercialized. This new molecule, by combining two distinct mechanisms of action, $\mu$-opioid receptor agonism (MOR) and noradrenaline reuptake inhibition (NRI), introduces a new pharmacological class called MOR-NRI (28). The synergistic interaction of the two combined effects offers particular advantages in terms of efficacy and tolerability. Analgesia is obtained at different levels through modulation of the opioid system and the descending inhibitory noradrenergic systems. The NRI mechanism of action leads to increased noradrenergic activity at the spinal level, through activation of the inhibitory descending pathways where noradrenaline is an important transmitter. The MOR therapeutic effect enhances the action of opioids at the spinal level, where they reduce the transmission of pain signal from the primary afferents to the spinothalamic tract fibers. At a supraspinal level, opioids contribute to activate the descending noradrenergic inhibitory projection to the spinal cord (29). Indeed, several preclinical pain models demonstrate that, despite a 50 -fold lower affinity for the MOR, tapentadol is only 2- to 3-fold less potent than morphine, clearly indicating that the NRI component of tapentadol contributes to its analgesic effect in an additive and synergistic manner (30). The two mechanisms of action result in different modulation of acute and chronic pain. The $\mu$-opioid agonism is, in fact, primarily effective in controlling acute pain, whereas noradrenaline reuptake inhibition is mainly implicated in modulating chronic pain (2). The efficacy of tapentadol in neuropathic pain conditions has been demonstrated in a number of experimental models. In this setting, tapentadol shows even higher potency than morphine (ED50 $=0.32 \mathrm{mg} / \mathrm{kg}$ vs $0.65 \mathrm{mg} / \mathrm{kg}$ in diabetic neuropathy) (30). The inhibitory effect on disease-related hyperalgesia suggested a superior efficacy profile of tapentadol compared with classical opioid, including morphine, in a rodent animal model of heat hyperalgesia (31). Efficacy on neuropathic pain has 
also been reported in clinical studies, especially in controlling chronic back pain with radicular involvement (32) and diabetic neuropathy (33). The MOR-NRI mechanism of action can finally give advantages in terms of tolerability. Tapentadol's noradrenergic components has an opioid-sparing effect, thus reducing GI adverse effects compared to traditional opioids. This new molecule also has minimum effect on serotonin reuptake, reducing its effects on the enteric nervous system (constipation, nausea and vomiting) (2). The safety profile is improved by the fact that no relevant interactions with enzymes of the P450 cytochrome system have been registered. The drug binding to plasma protein is low, reducing pharmacokinetic interaction with other medications (2).

Randomized clinical trials (RCT) have consistently demonstrated the efficacy and tolerability of tapentadol prolonged release (PR) (100-250 mg bid) in the management of moderate to severe chronic pain caused by OA and low back pain. (Table I). A metanalysis on efficacy data (34) was performed using results from $3 \mathrm{RCT}$ of tapentadol PR (100-250 mg bid) compared with placebo and oxycodone controlled release (20-50 $\mathrm{mg}$ bid) in the treatment of OA knee pain (35) and chronic low back pain (36). Tapenatodol PR analgesic efficacy resulted to be non-inferior to that provided by oxycodone $(20-50 \mathrm{mg}$ bid $)(\mathrm{p}<0.0001)$, but with a more favourable tolerability profile, particularly regarding GI adverse events (lower rates of nausea, vomiting, constipation) and central nervous system side effects. Also the analyses of $30 \%$ and $50 \%$ responders, patient global impression of change, Short-Form36 scores (SF-36) and the EuroQol 5-dimension health status index (EQ-5D) were all significantly improved with tapentadol compared to oxycodone $(\mathrm{p} \leq 0.048) \quad(35)$. Figure 1 and 2.

Comparable results were recently reported by Afilafo et al. (37), confirming the efficacy of tapentadol ER for different types of nociceptive (chronic osteoarthritis knee pain and low back pain) and neuropathic pain (diabetic peripheral neuropathy) over up to one year of treatment, maintaining a better tolerability profile compared to oxycodone.

Another recent phase $3 \mathrm{~b}$ study evaluated the effectiveness and tolerability of tapentadol PR, associated with tapentadol immediate release on-demand, for severe chronic OA knee pain, inadequately managed with WHO step I or II analgesics (38). A significant improvement in pain intensity from baseline through week 1 was demonstrated $(p<0.0001)$. Responder rate (the percentage of patients with a decrease in average pain intensity of $\geq 1$ point on a NRS-3 scale: 11-point numerical rating scale ranging 0-10) was $96.9 \%$, associated with high satisfaction ratings. All the subscale scores and the global score of the WOMAC (Western Ontario and McMaster Universities osteoarthritis index), a self-administered questionnaire used to assess pain, disability and joint stiffness in knee and hip OA, significantly improved from baseline to weeks 6,8, and 12. Quality of life was also improved by tapentadol treatment, as demonstrated by significantly improved scores in the EQ-5D and SF-36 physical and mental components. Significant reduction of anxiety and depression reported by patients were also recorded (39). Side effects were reported by $71 \%$ of patients (leading to study discontinuation in $12.5 \%$ of patients). The majority of adverse events (95.7\%) were considered to be of mild or moderate intensity, mainly affecting the GI system (39).

Tapentadol proved to be effective also in the management of neuropathic pain in the setting of severe chronic low back pain that was inadequately managed with WHO step I and II analgesics (39).

Significant improvements in pain intensity and neuropathic pain symptoms have been observed on an open-label, phase 3 study analyzing the effect of tapentadol vs strong opioids in the management of chronic low back pain (33). Patients responding to WHO step III opioids, but with scarce tolerability, were selected to receive tapentadol PR. Pain relief was comparable to equianalgesic doses of strong opioids, but with improved tolerability. Neuropathic pain component of low back pain was as- 
Table I - Main RCT evaluating the role of tapentadol in managing chronic musculoskeletal pain (OA and LBP) $(32,34-38,46)$.

\begin{tabular}{|c|c|c|c|c|c|c|c|}
\hline Author, year & $\begin{array}{l}\text { Type of } \\
\text { study }\end{array}$ & No. & $\begin{array}{l}\text { Cause of } \\
\text { chronic pain }\end{array}$ & $\begin{array}{l}\text { Control } \\
\text { group }\end{array}$ & $\begin{array}{l}\text { Study } \\
\text { period }\end{array}$ & Results & $\begin{array}{l}\text { Discontinuation } \\
\text { due to } A E\end{array}$ \\
\hline $\begin{array}{l}\text { Afilafo, } \\
2010^{*}\end{array}$ & $\begin{array}{l}\text { Multicentre, } \\
\text { double blind, } \\
\text { phase III }\end{array}$ & 1023 & OA knee pain & $\begin{array}{l}\text { Oxycodone, } \\
\text { placebo }\end{array}$ & 15 wks & $\begin{array}{l}\text { - } \geq 50 \% \text { improvement of pain } \\
\text { intensity in } 32 \% \text { for TP PR } \\
\text { vs } 24.3 \% \text { for OX CR ( } p=0.027)\end{array}$ & $\begin{array}{l}19,2 \% \text { TP PR } \\
\text { vs } 42,7 \% \text { OX CR } \\
\text { (Gl } 43 \% \text { vs } 67,3 \% \text { ) }\end{array}$ \\
\hline NCT00486811* & $\begin{array}{l}\text { Double blind } \\
\text { randomized } \\
\text { phase III }\end{array}$ & 987 & OA knee pain & $\begin{array}{l}\text { Oxycodone, } \\
\text { placebo }\end{array}$ & 15 wks & $\begin{array}{l}\text { - Differences in reduction } \\
\text { of pain intensity not statistically } \\
\text { significant between TP PR, } \\
\text { OX CR and placebo }\end{array}$ & $\begin{array}{l}18,8 \% \text { TP PR } \\
\text { vs } 40,7 \% \\
\text { OX CR }\end{array}$ \\
\hline $\begin{array}{l}\text { Buynak, } \\
2010^{*}\end{array}$ & \begin{tabular}{|l|} 
Prospective, \\
randomized, \\
double-blind, \\
phase III study
\end{tabular} & 981 & OA knee pain & $\begin{array}{l}\text { Oxycodone, } \\
\text { placebo }\end{array}$ & 15 wks & $\begin{array}{l}\text { - Reduction in pain intensity } \\
\text { (-2.9 for TP PR and } O X C R \\
\text { vs }-2.1 \text { for placebo) } p<0.001 \\
\text { - Lower incidence of } A E\end{array}$ & $\begin{array}{l}\text { 16.7\% TP PR } \\
\text { vs } 31.7 \% \text { OX CR } \\
\text { (Gl } 43.7 \% \\
\text { vs } 61.9 \% \\
\text { OX CR) }\end{array}$ \\
\hline Wild, 2010 & $\begin{array}{l}\text { Open label, } \\
\text { phase III }\end{array}$ & 1117 & $\begin{array}{l}\text { OA knee } \\
\text { or hip pain } \\
\text { and LBP }\end{array}$ & Oxycodone & 52 wks & $\begin{array}{l}\text { - Sustained long-term efficacy } \\
\text { - Better Gl tolerability }\end{array}$ & $\begin{array}{l}\text { 22.1\% TP PR } \\
\text { vs 36.8\% OX } \\
\text { CR (GI 8.6\% } \\
\text { vs } 21.5 \%)\end{array}$ \\
\hline $\begin{array}{l}\text { Steigerwald, } \\
2012\end{array}$ & $\begin{array}{l}\text { Open-label, } \\
\text { phase IIIIb }\end{array}$ & 224 & OA knee pain & $\begin{array}{l}\text { WHO step I } \\
\text { or II analgesics }\end{array}$ & 7 wks & $\begin{array}{l}\text { - } \text { Responder rate: } 96.9 \% \\
\text { - Satisfaction rate: up to } 92 \% \\
\text { - Improvement in WOMAC } \\
\text { - } \quad \text { scores }(p<0.0001) \\
\text { - Improved SF-36 }(p<0.05)\end{array}$ & $\begin{array}{l}12.5 \% \\
\text { (nausea, } \\
\text { constipation) }\end{array}$ \\
\hline Gàlvez, 2013 & \begin{tabular}{|l|} 
Multicenter, \\
multinational, \\
open-label, \\
phase Illb
\end{tabular} & 342 & $\begin{array}{l}\text { Chronic } \\
\text { back pain } \\
\text { (+/-neuropathic) } \\
\text { with poor } \\
\text { tolerability } \\
\text { to previous } \\
\text { opioids }\end{array}$ & Strong opioids & 12 wks & $\begin{array}{l}\text { - Responder rate: } 80.9 \% \text {. } \\
\text { - Satisfaction rate up to } 82.8 \% \\
\text { - Reduction of PainDETECT } \\
\text { - } \quad \text { score }(p<0.05) \\
\text { - Improved SF-36 }(p<0.05) \\
\text { - } \quad \text { Comparable pain relief } \\
\text { - Improved tolerability }\end{array}$ & $\begin{array}{l}14.4 \% \\
\text { (nausea, } \\
\text { vomiting, } \\
\text { dizziness) }\end{array}$ \\
\hline Baron, 2015 & \begin{tabular}{|l|} 
Multicenter, \\
multinational, \\
open-label, \\
phase Illb
\end{tabular} & 288 & $\begin{array}{l}\text { LBP with a } \\
\text { neuropathic } \\
\text { component }\end{array}$ & $\begin{array}{l}\text { TP PR lower } \\
\text { dose }+ \\
\text { Pregabalin }\end{array}$ & 8 wks & $\begin{array}{l}\text { - Effectiveness non inferior to } \\
\text { control group } \\
\text { - Mean pain intensity } \\
\text { - decreased }-3.9 \text { vs }-4.3 \\
\text { - PainDETECT }-9.7 \text { vs }-10.9 \\
\text { - Lower dizziness/somnolence } \\
16.9 \% \text { vs } 27 \%\end{array}$ & $\begin{array}{l}51 \% \\
\text { (serious AE } \\
3.2 \% \text { vs } 1.9 \% \text { ) }\end{array}$ \\
\hline Baron, 2015 & \begin{tabular}{|l|} 
Multicenter, \\
open label, \\
phase Illb trial, \\
continuation \\
arm
\end{tabular} & 309 & $\begin{array}{l}\text { LBP with a } \\
\text { neuropathic } \\
\text { component } \\
\text { having reached } \\
\text { pain control } \\
\text { with TP PR } \\
300 \mathrm{mg} / \text { day } \\
\text { (continuation } \\
\text { arm) }\end{array}$ & $\begin{array}{l}\text { TP } 500 \mathrm{mg} / \\
\text { day or TP PR } \\
\text { + pregabalin } \\
\text { (comparative } \\
\text { arm) for } \\
\text { patients } \\
\text { who had not } \\
\text { adequately } \\
\text { responded } \\
\text { to TP PR } \\
300 \mathrm{mg} / \text { day }\end{array}$ & $8 w k s$ & $\begin{array}{l}\text { - Mean pain intensity improved } \\
\text { (mean change: - } 5.3 \text { continuation } \\
\text { arm; - } 2.5 \text { comparative arm) } \\
\text { - Patient global impression to } \\
\text { change: } 94.9 \% \\
\text { - Improved quality of life (SF-12), } \\
\text { anxiety and depression scales. } \\
\text { - PainDETECT: mean change: } \\
\text {-12.3 (continuation arm); } \\
\text {-4.6; -5.1 for comparative arm) }\end{array}$ & $\begin{array}{l}50.8 \% \text {, leading } \\
\text { to discontinuation } \\
\text { in } 5.1 \% \text { (nausea, } \\
\text { vomiting, } \\
\text { headache, } \\
\text { nervousness, } \\
\text { restlessness) }\end{array}$ \\
\hline
\end{tabular}

$\mathrm{OA}=$ osteoarthritis, $\mathrm{LBP}=$ low back pain. TP PR = tapentadol prolonged release $(50-250 \mathrm{bid})$. OX CR = oxycodone controlled release (20-50 bid). $\mathrm{AE}=$ adverse events, $\mathrm{Gl}=$ gastrointestinal side effects. ${ }^{*}$ Pooled analysis by Lange et al., 2010. 


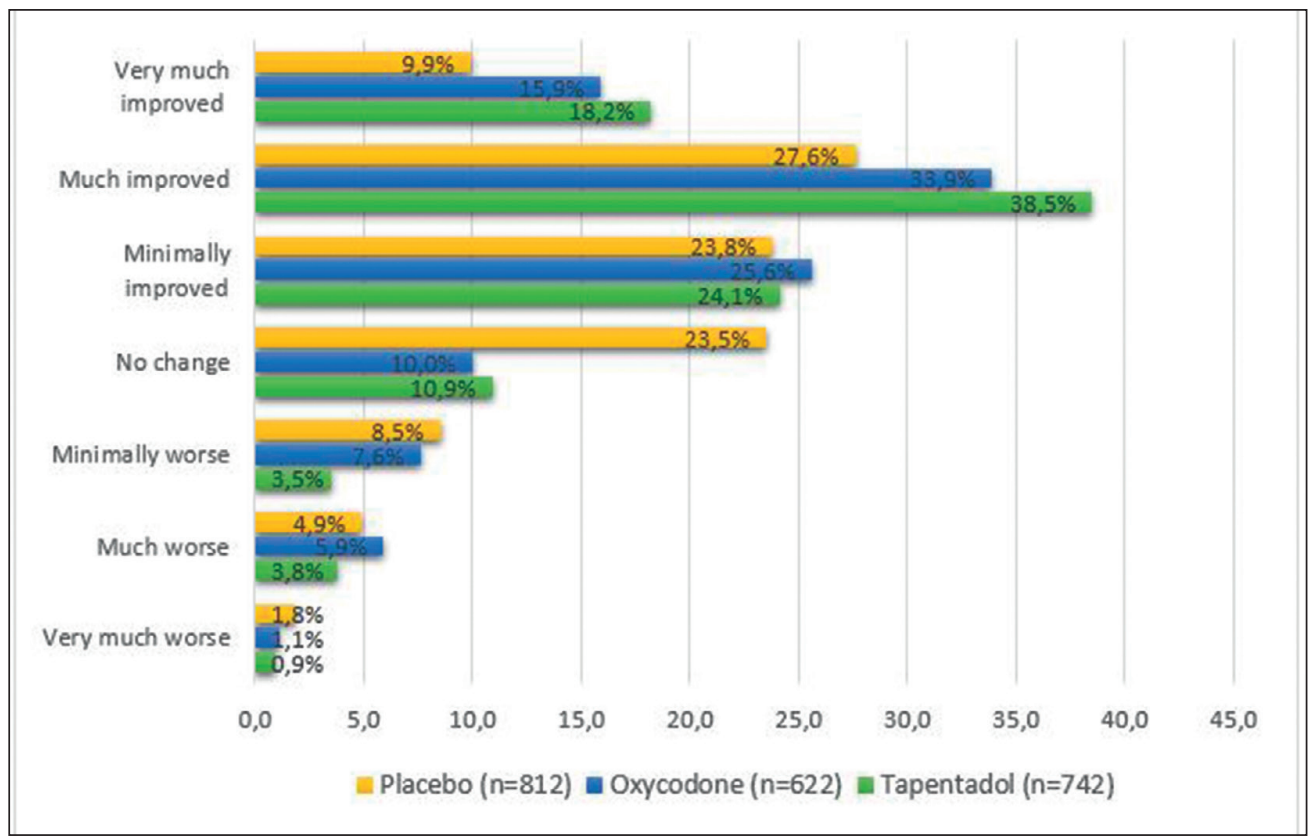

sessed using the painDETECT questionnaire or the Neuropathic Pain Symptom Inventory (NPSI). PainDETECT is a highly sensitive tool that addresses frequency and quality of neuropathic pain symptoms, pain patterns over time and radiating pain (33, 40). The Neuropathic Pain Symptom Inventory (NPSI) is a validated measure addressing different qualities of spontaneous, ongoing or paroxysmal pain, evoked pain and dysesthesia or paresthesia together with frequency and duration of pain (33, 41). Both painDETECT and NPSI significantly improved with tapentadol treatment. In line with previous studies, also measures of quality of life, health status, function and patient satisfaction increased substantially (33). In 2015, a Cochrane review analysed the available evidence concerning the use of Tapentadol for chronic musculoskeletal

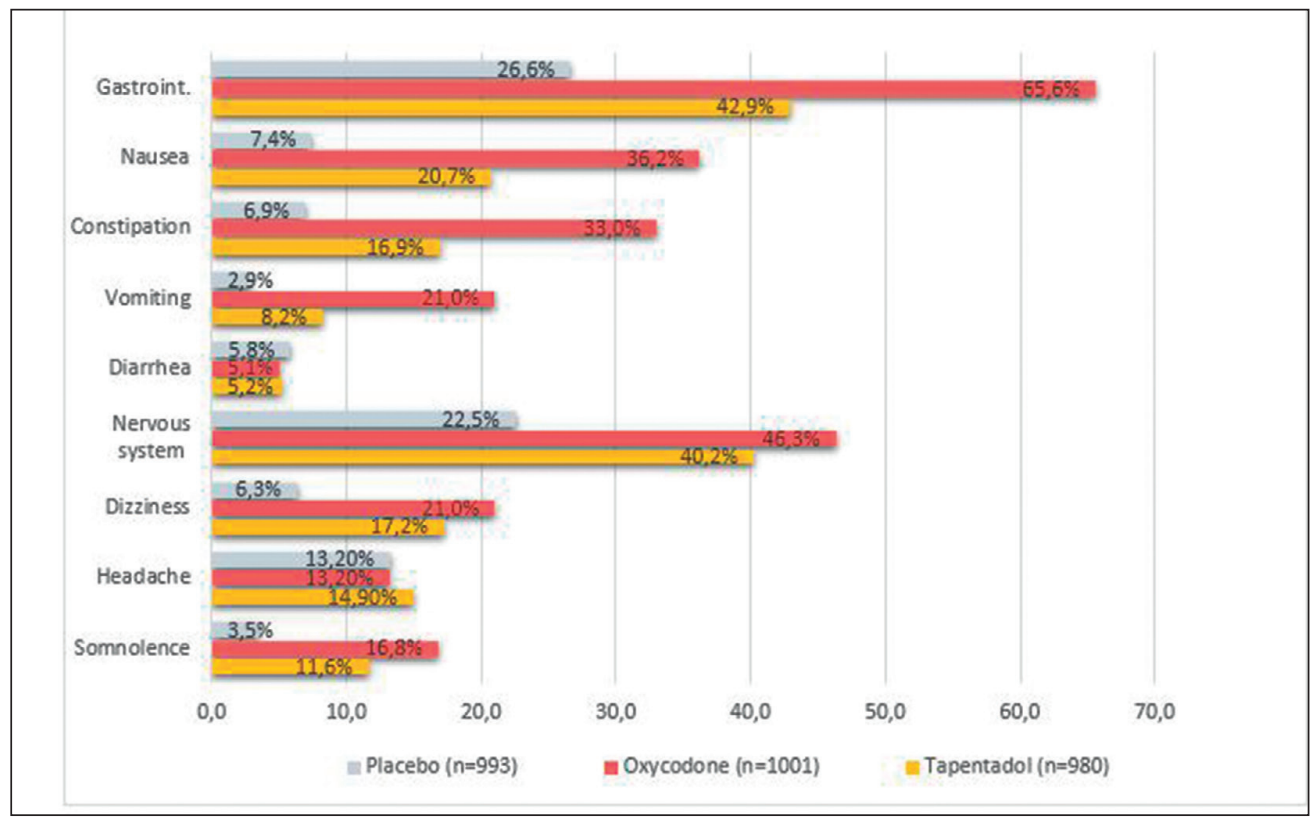

Figure 2 - Treatment emergent adverse events.

Data from Pooled analysis by Lange et al (34). Significant lower incidence of Gl adverse events in the tapentadol group compared to oxycodone $(p<0.001)$. Gastroint. = gastrointestinal side effects. 
pain in adults. The authors included data on 4094 patients with LBP and/or OA enrolled in several RCTs. All trials were oxycodonecontrolled and sometimes accepted the use of placebo. When compared to placebo, TP PR demonstrated a mean reduction of 0.56 points $(95 \%$ CI $0.92-0.2)$ on a 11-pointNRS scale at 12 weeks of follow up, with a $36 \%$ probability of responding to treatment. The risk of discontinuation due to side effects during treatment with TP PR increased of 2.7 fold. In the oxycodonecontrolled analyses, TP PR showed a 0.24 points (95\% CI 0.43-0.05) reduction in pain intensity. The possibility to respond to treatment did not reach statistical significance. The high heterogeneity of the efficacy estimates may account for some of the suboptimal results. Nevertheless, TP PR confirmed the good tolerability profile with a $50 \%$ reduction in the risk of discontinuation due to side effects and a $9 \%$ reduction in the overall adverse events occurrence risk compared to oxycodone (42).

Ongoing studies with promising results are also exploring the use of Tapentadol in the management of fibromyalgia not responding to standard therapy.

Long term safety of tapentadol in the treatment of chronic OA and low back pain has been evaluated for up to one year in a Phase III, open-label, randomized study including 1117 patients (43). Patients were randomized 4:1 to receive tapentadol PR or oxycodone CR. Tapentadol provided stable, long-term relief from chronic pain and was associated with significantly lower levels of constipation $(22.6 \%$ vs $38.6 \%$; $\mathrm{p}<0.001)$, nausea $(18.1 \%$ vs $33.2 \%$; $\mathrm{p}<0.001)$, and vomiting $(7.0 \%$ vs $13.5 \%$; $\mathrm{p}=0.002)$ compared to oxycodone. GI side effects led to study discontinuation in $8.6 \%$ and $21.5 \%$ of patients respectively (44). Tapentadol also showed minimal effects on adrenal, pituitary, hypothalamic and gonadal hormone production with lower rates of opioidinduced androgen deficiency compared to other $\mu$-opioid analgesics (2).

A high level of concern exists for the risk of abuse and diversion connected with opioids. In the United States opioids addiction and abuse is regarded as a major public health issue and is monitored through the Research Abuse, Diversion, and AddictionRelated Surveillance (RADARS) System. During the first 24 months following its introduction, Tapentadol immediate release (IR) showed a particularly favorable profile, with lower rates of abuse and diversion compared to oxycodone and hydrocodone $(44,45)$. Budget impact analysis of tapentadol PR for the treatment of moderate to severe chronic non-cancer pain have also showed a favourable economic profile driven by lower drug costs and daily average consumption and fewer opioid induced side effects (46).

\section{CONCLUSIONS}

Musculoskeletal conditions are the most frequent cause of chronic pain and affect around 1 in 5 adults in Europe. When chronic pain occurs, it becomes disease itself, with substantial clinical, psychological, social and economic impact. Pain is too often underestimated and inadequately treated; this is mainly due to tolerability problems connected with traditional analgesics and unjustified low prescription rates of opioids. Recently Tapentadol, a novel, centrally acting analgesic has been introduced for the treatment of chronic pain. This new molecule, by combining two distinct mechanisms of action, $\mu$-opioid receptor agonism (MOR) and noradrenaline reuptake inhibition (NRI), introduces a new pharmacological class called MOR-NRI. Tapentadol has shown promising results in the management of both nociceptive and neuropathic pain and good tolerability profile, particularly concerning GI side effects, compared to traditional opioids. Several studies have led to consistent and reproducible results on efficacy and tolerability profile of tapentadol, regardless of the type of chronic pain, study population, and methodological differences. This versatility is enabled by a molecule without active metabolites and a double mechanisms of action. This novel analgesic represents a possible therapeutic option also in the rheumatologic field, particularly in the treatment of osteoarthritis and low back 
pain. Further studies are needed to assess the role of tapentadol in the management of pain connected with inflammatory arthritis or caused by vasculitis.

\section{REFERENCES}

1. Woolf AD, Erwin J, March L. The need to address the burden of musculoskeletal conditions. Best Pract Res Clin Rheumatol. 2012; 26: $183-224$.

2. Pergolizzi J, Alegre C, Blake D, Alén JC, Caporali R, Casser HR, Correa-Illanes G, Fernandes P, Galilea E, Jany R, Jones A, Mejjad O, Morovic-Vergles J, Oteo Álvaro A, Radrigán Araya FJ, Simões ME, Uomo G. Current considerations for the treatment of severe chronic pain: the potential for tapentadol. Pain Pract. 2012; 12: 290-306.

3. Bonica JJ. The Management of Pain. Lea and Febiger: Philadelphia. 1953.

4. Montecucco C, Cavagna L, Caporali R. Pain and rheumatology. Eur J Pain. 2009; 3: (Suppl.) $123-127$.

5. European Commission. Jealth in the European Union. Special Eurobarometer. 2007; 272.

6. Salaffi F, De Angelis R, Grassi W. MArche Pain Prevalence; INvestigation Group (MAPPING) study. Prevalence of musculoskeletal conditions in an Italian population sample: results of a regional community-based study. I. The MAPPING study. Clin Exp Rheumatol. 2005; 23: 819-28.

7. McBeth J, Jones K. Epidemiology of chronic musculoskeletal pain. Best Pract Res Clin Rheumatol. 2007; 21: 403-25.

8. European Commission. Health in the European Union. Special Eurobarometer. 2007; 272.

9. Langley PC. The prevalence, correlates and treatment of pain in the European Union. Curr Med Res Opin. 2011; 27: 463-80.

10. Scarpa R, Sarzi-Puttini P, Cimmino MA, Caporali R, Parazzini F, Zaninelli A, Canesi B. Analysis of pharmacologic and nonpharmacologic prescription patterns of general practitioners and specialists in the AMICA study. Semin Arthritis Rheum. 2005; 35 (Suppl. 1): 24-30.

11. Salaffi F, De Angelis R, Stancati A, Grassi W. MArche Pain; Prevalence INvestigation Group (MAPPING) study. Health-related quality of life in multiple musculoskeletal conditions: a cross-sectional population based epidemiological study. II. The MAPPING study. Clin Exp Rheumatol. 2005; 23: 829-39.

12. Zhang W, Moskowitz RW, Nuki G, Abramson S, Altman RD, Arden N, Bierma-Zeinstra S, Brandt KD, Croft P, Doherty M, Dougados M, Hochberg M, Hunter DJ, Kwoh K, Lohmander LS, Tugwell P. OARSI recommendations for the management of hip and knee osteoarthritis,
Part II: OARSI evidence-based, expert consensus guidelines. Osteoarthritis Cartilage. 2008; 16. 137-62.

13. Cimmino MA, Salaffi F. The fate of the patient with musculoskeletal disorders in Italy: an epidemiological insight. Clin Exp Rheumatol. 2007; 25: 803-5.

14. De Leon-Casasola OA. Opioids for chronic pain: new evidence, new strategies, safe prescribing. Am J Med. 2013; 126 (3 Suppl. 1): S3-11.

15. Ausiello JC, Stafford RS. Trends in medication use for osteoarthritis treatment.. J Rheumatol. 2002; 29: 999-1005.

16. Alacqua M, Trifirò G, Cavagna L, Caporali R, Montecucco CM, Moretti S, Tari DU, Galdo M, Caputi AP, Arcoraci V. Prescribing pattern of drugs in the treatment of osteoarthritis in Italian general practice: the effect of rofecoxib withdrawal. Arthritis Rheum. 2008; 59: 56874.

17. Kaye AD, Baluch A, Scott JT. Pain Management in the Elderly Population: A Review. Ochsner J. 2010 Fall; 10: 179-87.

18. Chaparro LE, Furlan AD, Deshpande A, Mailis-Gagnon A, Atlas S, Turk DC. Opioids compared to placebo or other treatments for chronic low-back pain. Cochrane Database Syst Rev. 2013; 27: CD004959.

19. Antman EM, Bennett JS, Daugherty A, Furberg C, Roberts H, Taubert KA. Use of nonsteroidal antiinflammatory drugs: an update for clinicians: a scientific statement from the American Heart Association. Circulation. 2007; 115: 1634-42.

20. Chou R, Huffman LH. American Pain Society; American College of Physicians. Medications for acute and chronic low back pain: a review of the evidence for an American Pain Society/ American College of Physicians clinical practice guideline. Ann Intern Med. 2007; 147: 505-14.

21. Avouac J, Gossec L, Dougados M. Efficacy and safety of opioids for osteoarthritis: a metaanalysis of randomized controlled trials. Osteoarth Cartil. 2007; 15: 957-65.

22. Varrassi G, Müller-Schwefe G, Pergolizzi J, Orónska A, Morlion B, Mavrocordatos P, Margarit C, Mangas C, Jaksch W, Huygen F, Collett B, Berti M, Aldington D, Ahlbeck K. Pharmacological treatment of chronic pain the need for CHANGE. Curr Med Res Opin. 2010; 26: 1231-45.

23. Moore RA, McQuay HJ. Prevalence of opioid adverse events in chronic non-malignant pain: systematic review of randomised trials of oral opioids. Arthritis Res Ther. 2005; 7: R104651.

24. Baldini A, Von Korff M, Lin EH. A Review of Potential Adverse Effects of Long-Term Opioid Therapy: A Practitioner's Guide. Prim Care Companion CNS Disord. 2012; 14. 
25. Kroenke K, Krebs EE, Bair M. Pharmacotherapy of chronic pain: a synthesis of recommendations from systematic reviews. Gen Hosp Psychiatry. 2009; 31: 206-19.

26. Arendt-Nielsen L, Nie H, Laursen MB, et al. Sensitization in patients with painful knee osteoarthritis. Pain. 2010; 149: 573-81.

27. Dickenson AH. Commentary on: Opioid and noradrenergic contributions of tapentadol in experimental neuropathic pain. Neurosci Lett. 2013.

28. Kress H. Tapentadol and its two mechanisms of action: is there a new pharmacological class of centrally acting analgesics on the horizon? Eur J Pain. 2010; 14: 781-3.

29. Schröder W, Tzschentke TM, Terlinden R, De Vry J, Jahnel U, Christoph T, Tallarida RJ. Synergistic interaction between the two mechanisms of action of tapentadol in analgesia. J Pharmacol Exp Ther. 2011; 337: 312-20.

30. Tzschentke TM, Jahnel U, Kogel B, Christoph T, Englberger W, De Vry J, Schiene K, Okamoto A, Upmalis D, Weber H, Lange C, Stegmann JU, Kleinert R. Tapentadol hydrochloride: a next-generation, centrally acting analgesic with two mechanisms of action in a single molecule. Drugs Today (Barc). 2009; 45: 483-96.

31. Christoph T, De Vry J, Tzschentke TM. Tapentadol, but not morphine, selectively inhibits disease-related thermal hyperalgesia in a mouse model of diabetic neuropathic pain. Neurosci Lett. 2010; 470: 91-4.

32. Gálvez R, Schäfer M, Hans G, Falke D, Steigerwald I. Tapentadol prolonged release versus strong opioids for severe, chronic low back pain: results of an open-label, phase $3 \mathrm{~b}$ study. Adv Ther. 2013; 30: 229-59.

33. Schwartz S, Etropolski M, Shapiro DY, Okamoto A, Lange R, Haeussler J, Rauschkolb C. Safety and efficacy of tapentadol ER in patients with painful diabetic peripheral neuropathy: results of a randomized-withdrawal, placebo-controlled trial. Curr Med Res Opin. 2011; 27: 151-62.

34. Lange B, Kuperwasser B, Okamoto A, Steup A, Haufel T, Ashworth J, Etropolski M. Efficacy and safety of tapentadol prolonged release for chronic osteoarthritis pain and low back pain. Adv Ther. 2010; 27: 381-99.

35. Afilalo M, Etropolski MS, Kuperwasser B, Kelly K, Okamoto A, Van Hove I, Steup A, Lange B, Rauschkolb C, Haeussler J. Efficacy and safety of tapentadol extended release compared with oxycodone controlled release for the management of moderate to severe chronic pain related to osteoarthritis of the knee: A randomized, double-blind, placebo- and activecontrolled phase III study. Clin Drug Investig. 2010; 30: 489-505.

36. Buynak R, Shapiro DY, Okamoto A, Van Hove I, Rauschkolb C, Steup A, Lange B, Lange C,
Etropolski M. Efficacy and safety of tapentadol extended release for the management of chronic low back pain: Results of a prospective, randomized, double-blind, placebo- and activecontrolled Phase III study. Expert Opin Pharmacother. 2010; 11: 1787-804.

37. Afilafo M, Morlion B. Efficacy of tapentadol ER for managing moderate to severe chronic pain. Pain Physician. 2013; 16: 27-40.

38. Steigerwald I, Müller M, Kujawa J, Balblanc JC, Calvo-Alén J. Effectiveness and safety of tapentadol prolonged release with tapentadol immediate release on-demand for the management of severe, chronic osteoarthritis-related knee pain: results of an open-label, phase $3 \mathrm{~b}$ study. J Pain Res. 2012; 5: 121-38.

39. Steigerwald I, Müller M, Davies A, Samper D, Sabatowski R, Baron R, Rozenberg S, Szczepanska-Szerej A, Gatti A, Kress HG. Effectiveness and safety of tapentadol prolonged release for severe, chronic low back pain with or without a neuropathic pain component: results of an open-label, phase $3 \mathrm{~b}$ study. Curr Med Res Opin. 2012; 28: 911-36.

40. Freynhagen R, Baron R, Gockel U, Tölle TR. painDETECT: a new screening questionnaire to identify neuropathic components in patients with back pain. Curr Med Res Opin. 2006; 22: 1911-20.

41. Bouhassira D, Attal N, Fermanian J, Alchaar H, Gautron M, Masquelier E, Rostaing S, Lanteri-Minet M, Collin E, Grisart J, Boureau F. Development and validation of the Neuropathic Pain Symptom Inventory. Pain. 2004; 108: 248-57.

42. Santos J, Alarcão J, Fareleira F, Vaz-Carneiro A, Costa J. Tapentadol for chronic musculoskeletal pain in adults. Cochrane Database Syst Rev. 2015; 5: CD009923. [Epub ahead of print].

43. Wild JE, Grond S, Kuperwasser B, Gilbert J, McCann B, Lange B, Steup A, Häufel T, Etropolski MS, Rauschkolb C, Lange R. Long-term safety and tolerability of tapentadol extended release for the management of chronic low back pain or osteoarthritis pain. Pain Pract. 2010; 10: 416-27.

44. Dart RC, Cicero TJ, Surratt HL, Rosenblum A, Bartelson BB, Adams EH. Assessment of the abuse of tapentadol immediate release: the first 24 months. J Opioid Manag. 2012; 8: 395-402.

45. Butler SF, McNaughton EC, Black RAPain Med. Tapentadol abuse potential: a postmarketing evaluation using a sample of individuals evaluated for substance abuse treatment. Pain Med. 2015; 16: 119-30.

46. Merchant S, Noe LL, Howe A, Duff S, Gricar J, Ogden K, Mody SH. Budget impact analysis of Tapentadol extended release for the treatment of moderate to severe chronic noncancer pain. Clinical Therapeutics 2013; article in press. 